\title{
Reductions in muscle sympathetic nerve activity after long term metoprolol for dilated cardiomyopathy: preliminary observations
}

Division of Cardiology and the Centre for Cardiovascular Research, The

Toronto Hospital and University of Toronto, Toronto, Ontario, Canada

M A Rahman

K Hara

P A Daly

E D Wigle

J S Floras

Correspondence to:

Dr J S Floras, Mount Sinai

Hospital, Suite 1615,600

University Avenue, Toronto

University Avenue, Toronto,

Accepted for publication

22 May 1995

\begin{abstract}
Objective-To determine whether efferent muscle sympathetic nerve activity diminishes in subjects with dilated cardiomyopathy who improve after long term treatment with metoprolol.

Methods-Microneurographic, echocardiographic, plethysmographic, and neurohumoral data were obtained immediately before and 20 months after the addition of $\beta$ blockade in seven subjects with idiopathic dilated cardiomyopathy with clinical deterioration despite conventional treatment.

Results-Six subjects (three men, three women, aged 24-62 years) were restudied after a mean (SEM) of $20(2 \cdot 4)$ months treatment with metoprolol $(45 \cdot 8(2 \cdot 6)$ mg/d). Long term treatment was associated with decreases in left ventricular end diastolic and end systolic diameter $(P<0.005)$, left ventricular mass index $(P<0.05)$, and atrial natriuretic factor $(P<0.05)$, and increases in fractional shortening $(P<0.05)$ and mean blood pressure $(P<0.05)$. There was a $50 \%$ reduction in peroneal muscle sympathetic nerve activity (from $49.2(10 \cdot 1)$ to $24.5(4.7)$ bursts/min; $(P<0.005)$ and $a$ $62 \%$ decrease in calf vascular resistance (from $56.2(4.4)$ to $21.2(5 \cdot 7)$ units; $P<0.005)$. This reduction in pulse synchronous nerve activity was not simply a function of bradycardia (heart rate fell from $94.2(4 \cdot 6)$ to $62.8(5 \cdot 7)$ beats/min; $P<0.005)$ since muscle sympathetic burst incidence also decreased (from $51(8 \cdot 7)$ to $37.5(5 \cdot 2)$ bursts/100 heart beats; $P<$ $0 \cdot 05)$. Similar haemodynamic improvement was observed in the seventh subject, who was switched to sotalol 200 mg/d and restudied after 20 months, but burst frequency was $\mathbf{5 0 \%}$ higher and calf vascular resistance $93 \%$ higher.

Conclusions-Muscle sympathetic nerve activity and calf vascular resistance decrease in patients with dilated cardiomyopathy who improve after long term treatment with metoprolol. Inhibition of central sympathetic outflow may be one mechanism by which metoprolol benefits such subjects.
\end{abstract}

(Br Heart f 1995;74:431-436)

Keywords: metoprolol; dilated cardiomyopathy; sympathetic nerve activity
Sympathetic nervous system activation is an important marker for adverse outcome in congestive heart failure. ${ }^{1}$ Although the mechanisms responsible for this disturbance have not been fully elucidated, ${ }^{2-4}$ its adverse consequences for the failing myocardium have been well documented. ${ }^{35-7}$

In 1975 Waagstein and coworkers reported symptomatic and haemodynamic improvement after short term $\beta$ adrenoceptor blockade in seven patients with idiopathic dilated cardiomyopathy. ${ }^{8}$ These observations provided the impetus for subsequent studies of chronic $\beta$ adrenoceptor blockade in selected patients. Recently, a placebo controlled multicentre trial reported a favourable impact of metoprolol on symptoms, cardiac function, and disease progression in this condition. ${ }^{9}$

Reversal of $\beta$ adrenoceptor downregulation or uncoupling are two of the presumed benefits of chronic $\beta$ adrenoceptor blockade in congestive heart failure. ${ }^{10}$ Its effects on central sympathetic outflow are not known. $\beta$ Adrenoceptor antagonists might oppose the actions of catecholamines on postjunctional adrenoceptors in the heart and the peripheral circulation without attenuating sympathetic outflow to heart, kidney, and peripheral vasculature. Indeed, by reducing discharge from cardiac mechanoreceptors with inhibitory vagal afferents, the negative inotropic properties of $\beta$ adrenoceptor blockers might cause a reflex increase in sympathetic nerve traffic. ${ }^{11}$

Alternatively, $\beta$ adrenergic antagonists might attenuate sympathetic drive to the heart and periphery through a central or reflex action. Wallin et $a l^{12}$ observed reductions in both blood pressure and muscle sympathetic nerve burst frequency in hypertensive subjects restudied after four months of oral metoprolol. Noradrenaline release across the failing human heart may be attenuated by carvedilol. ${ }^{13}$ We undertook this study to test the hypothesis that efferent muscle sympathetic nerve activity diminishes in those subjects with dilated cardiomyopathy who improve after long term treatment with metoprolol.

\section{Methods}

SUBJECTS

Seven subjects with idiopathic dilated cardiomyopathy (four men, three women, mean (SEM) age 37 (5) years, range 24-62 years), were referred for this study by their attending cardiologists in anticipation of starting $\beta$ adrenergic blockade treatment with metopro- 
Table 1 Subject characteristics

\begin{tabular}{|c|c|c|c|c|c|c|c|c|c|c|c|c|c|}
\hline Subject & $\begin{array}{l}\text { Age } \\
\text { (years) }\end{array}$ & Sex & $\begin{array}{l}\text { Dose } \\
(m g)\end{array}$ & Duration & $\begin{array}{l}\text { Weight } \\
(\mathrm{kg})\end{array}$ & $\begin{array}{l}B S A \\
\left(m^{2}\right)\end{array}$ & $\begin{array}{l}\text { NYHA } \\
\text { class }\end{array}$ & $E F \%$ & Treatment & $\begin{array}{l}S B P \\
(m m H g)\end{array}$ & $\begin{array}{l}D B P \\
(m m H g)\end{array}$ & $\begin{array}{l}H R \\
\text { (beats/min) }\end{array}$ & $\begin{array}{l}\text { MSNA } \\
\text { bursts/min) }\end{array}$ \\
\hline \multicolumn{14}{|c|}{$\begin{array}{l}\text { (A) First study: immediately before } \beta \text { blockade } \\
\text { Subjects restudied on metoprolol }\end{array}$} \\
\hline 1 & 29 & $\mathrm{~F}$ & & & 48 & $1 \cdot 454$ & II & 15 & $\mathrm{ADFC}$ & 88 & 51 & 103 & 66 \\
\hline 2 & 28 & $\mathrm{~F}$ & & & 65 & 1.714 & III & 16 & $\mathrm{ADFH}$ & 89 & 53 & 81 & 48 \\
\hline 3 & 62 & $\mathrm{~F}$ & & & 62 & 1.702 & III & 14 & $\mathrm{ADFC}$ & 97 & 72 & 88 & 37 \\
\hline 4 & 36 & M & & & 95 & $2 \cdot 174$ & II & 18 & $\mathrm{AC}$ & 95 & 49 & 84 & 20 \\
\hline 5 & 34 & M & & & 82 & 2.023 & II & 10 & $\mathrm{ADFC}$ & 114 & 63 & 108 & 89 \\
\hline 6 & 24 & M & & & 73 & 1.934 & IV & 10 & DH & 92 & 54 & 101 & 35 \\
\hline Mean & $35 \cdot 5$ & & & & $70 \cdot 8$ & & & 14 & & 96 & 57 & 94 & 49 \\
\hline SD & $13 \cdot 7$ & & & & 16.5 & & & $3 \cdot 3$ & & $9 \cdot 5$ & $8 \cdot 8$ & 11 & 25 \\
\hline \\
\hline (B) Seco & study & M & & & 79 & 1.928 & III & 23 & $\mathrm{ADC}$ & 101 & 63 & 85 & 22 \\
\hline \multicolumn{14}{|c|}{ Subjects restudied on metoprolol } \\
\hline 1 & & & $\begin{array}{l}50 \\
37 \cdot 5\end{array}$ & $\begin{array}{l}16 \\
25\end{array}$ & $49 \cdot 5$ & $\begin{array}{l}1.500 \\
1.825\end{array}$ & I & & $\begin{array}{l}\mathrm{ADC} \\
\mathrm{AF}\end{array}$ & 121 & 66 & 75 & 24 \\
\hline $\begin{array}{l}2 \\
3\end{array}$ & & & 50 & $\begin{array}{l}25 \\
13\end{array}$ & 62 & $\begin{array}{l}1.823 \\
1.702\end{array}$ & I & & $\begin{array}{l}\mathrm{AF} \\
\mathrm{ADFC}\end{array}$ & $\begin{array}{l}124 \\
112\end{array}$ & $\begin{array}{l}67 \\
73\end{array}$ & 72 & 29 \\
\hline 4 & & & 50 & 15 & 100 & $2 \cdot 175$ & I & & ADFCAm & 92 & 51 & 43 & 12 \\
\hline 5 & & & 50 & 26 & 88 & $2 \cdot 119$ & I & & ADFC & 118 & 66 & 69 & 41 \\
\hline 6 & & & $37 \cdot 5$ & 24 & 73 & 1.934 & I & & $\mathrm{ADC}$ & 103 & 55 & 47 & 11 \\
\hline Mean & & & $45 \cdot 8$ & 20 & $74 \cdot 6$ & & & & & 112 & 63 & 63 & 25 \\
\hline SD & & & 6.45 & 6 & 18 & & & & & 12 & $8 \cdot 3$ & 14 & 12 \\
\hline \multicolumn{3}{|c|}{$\begin{array}{l}\text { Other subject } \\
7\end{array}$} & $S$ & 20 & 80 & 1.938 & I & & $\mathrm{ADC}$ & 121 & 73 & 70 & 33 \\
\hline
\end{tabular}

BSA, body surface area; NYHA, New York Heart Association functional class; EF, left ventricular ejection fraction; SBP, systolic blood pressure; DBP, diastolic blood pressure; HR, heart rate; MSNA, muscle sympathetic nerve activity; Dose, daily dose of metorpolol; Duration, months between first and second study; A, ACE inhibitors; D, digoxin; F, diuretics; C, coumarin; Am, amiodarone; H, heparin; S, sotalol (200 mg/d in this subject)

lol. All subjects had been admitted to hospital for the management of progressive congestive heart failure and met the following criteria: left ventricular ejection fraction $\leqslant 25 \%$, marked global hypokinesia, and a short axis left ventricular end diastolic dimension (LVDD) of $60 \mathrm{~mm}$ or more. Coronary artery disease and active myocarditis were excluded by coronary angiography and endocardial biopsy. None had concomitant medical conditions that might otherwise alter sympathetic nerve activity. All subjects suffered progressive clinical deterioration despite sodium restriction, and several months (mean 7 (3), range 1-22 months) of chronic treatment with diuretics $(n=4)$, digitalis $(n=6)$, and angiotensin converting enzyme (ACE) inhibitors $(n=6)$. One subject (No 6) was unable to tolerate ACE inhibition because of hypotension. All were on anticoagulants (table 1). At entry, mean reported New York Heart Association functional class was $2 \cdot 7$ $(0 \cdot 3)$. Their ejection fractions, as assessed by radionuclide ventriculography, ranged from $10 \%$ to $23 \%$ (mean $15(2) \%$ ). The decision to start metoprolol was made independently by the patients' own cardiologists.

PROCEDURES

Blood pressure was measured by an automatic cuff recorder (Physio Control Lifestat 200),

Immediately before metoprolol

After 26 months metoprolol

ECG
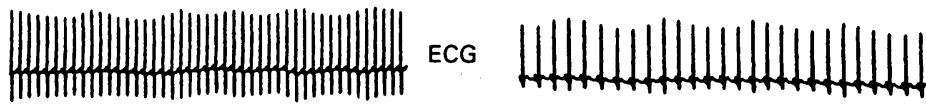

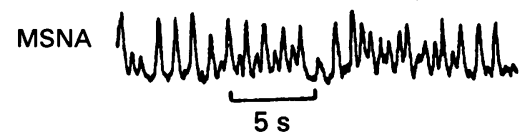

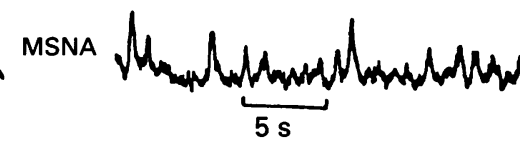

Figure 1 Electrocardiogram (ECG) and mean voltage neurograms of muscle sympathetic nerve activity (MSNA) of one dilated cardiomyopathy subject (No 5), studied immediately before (left panel) and after 26 months of treatment with metoprolol (right panel). Sympathetic nerve activity in this subject fell from 89 to 41 bursts/min. and heart rate was derived from lead II of the electrocardiogram. Calf blood flow $(\mathrm{ml} / \mathrm{min} / 100 \mathrm{ml}$ of calf volume) was estimated by venous occlusion plethysmography. ${ }^{14}$ Calf vascular resistance (expressed as resistance units) was calculated as the quotient of mean arterial pressure divided by the average of four to six measures of calf blood flow. Left ventricular dimensions were determined by $M$ mode echocardiography (Ultramark 8; Advanced Technology Laboratories) with subjects in the left lateral position. Left ventricular mass and mass index were calculated using the formula of Devereux and Reichek. ${ }^{15}$ Multiunit recordings of post-ganglionic muscle sympathetic activity were obtained from the peroneal nerve. ${ }^{16}$ Sympathetic activity was expressed as bursts/min (burst frequency) and bursts $/ 100$ cardiac cycles (burst incidence). The mean interobserver variability arising from visual evaluation of the microneurographic record in our laboratory is $3.9 \%$; the mean intra-observer variability is $4 \cdot 5 \%$.

\section{PROTOCOL}

After informed written consent, each subject underwent two identical studies, performed at the same time of the day: (1) baseline observations, immediately before starting $\beta$ adrenoceptor blockade; and (2) a follow up study an average of 20 (2) months later (fig 1). Following instrumentation, subjects rested supine for $20 \mathrm{~min}$ before any measurements. Blood pressures were obtained every minute. Heart rate, the electrocardiogram, and the mean voltage neurogram of muscle sympathetic nerve activity were recorded continuously for 15-20 min (Gould 2800S ink recorder). Calf blood flow was measured every $15 \mathrm{~s}$ over the last $2 \mathrm{~min}$ of this period, after which venous blood was withdrawn for determination of plasma noradrenaline and atrial natriuretic factor concentrations. Echocardiographic measurements were then obtained. These investigations were approved 
by our institutional human subjects review committee.

\section{$\beta$ ADRENOCEPTOR BLOCKADE}

Metoprolol was started by the attending cardiologist at doses as low as $5 \mathrm{mg}$ daily and gradually increased as tolerated. All subjects but one (subject No 3) were admitted to hospital for this purpose. Six subjects (Nos 1-6) were restudied after an average of 20 months on between 37.5 and $50 \mathrm{mg}$ of metoprolol daily (final average dose, $45 \cdot 8(2 \cdot 6) \mathrm{mg} / \mathrm{d}$ ) (table 1). One subject (No 7 in table 1) was able to tolerate metoprolol $50 \mathrm{mg}$ orally twice daily but because of non-sustained ventricular tachycardia was switched soon after to sotalol $200 \mathrm{mg} / \mathrm{d}$ and restudied while on that drug 20 months after his first study.

\section{STATISTICAL PROCEDURES}

Data were analysed with Systat $5 \cdot 2$ (Systat Intelligent Software) and are presented as mean (SEM), unless stated otherwise. Paired $t$ tests were applied to compare pre-treatment and post-treatment values.

Table 2 Haemodynamic, echocardiographic, and neurohumoral variables before and after long term treatment with metoprolol. Values are mean (SEM) for 6 subjects

\begin{tabular}{|c|c|c|}
\hline & Before $\beta$ blocker & Follow up \\
\hline $\begin{array}{l}\text { Haemodynamic data } \\
\text { Systolic blood pressure }(\mathrm{mm} \mathrm{Hg}) \\
\text { Mean blood pressure }(\mathrm{mm} \mathrm{Hg}) \\
\text { Diastolic blood pressure }(\mathrm{mm} \mathrm{Hg}) \\
\text { Heart rate (beats/min) } \\
\text { Calf blood flow }(\mathrm{ml} / \mathrm{min} / 100 \mathrm{ml})^{\mathrm{a}} \\
\text { Calf vascular resistance (units) }\end{array}$ & $\begin{array}{r}95 \cdot 8(3 \cdot 9) \\
69 \cdot 8(3 \cdot 3) \\
57 \cdot 0(3 \cdot 6) \\
94 \cdot 2(4 \cdot 6) \\
1 \cdot 2(0 \cdot 1) \\
56 \cdot 2(4 \cdot 4)\end{array}$ & $\begin{array}{c}112 \cdot 0(5)^{\star} \\
79 \cdot 2(3 \cdot 6)^{\star} \\
63 \cdot 0(3 \cdot 4) \\
62 \cdot 8(5 \cdot 7) \dagger \\
4.9(1)^{\star} \\
21 \cdot 2(5 \cdot 7) \dagger\end{array}$ \\
\hline $\begin{array}{l}\text { Echocardiographic data } \\
\text { Left ventricular end diastolic diameter }(\mathrm{cm}) \\
\text { Left ventricular end systolic diameter }(\mathrm{cm}) \\
\text { Fractional shortening }(\%) \\
\text { Left ventricular mass }(\mathrm{g}) \\
\text { Left ventricular mass index }\left(\mathrm{g} / \mathrm{m}^{2}\right)\end{array}$ & $\begin{array}{r}7 \cdot 1(0 \cdot 3) \\
6 \cdot 3(0 \cdot 2) \\
10 \cdot 7(1 \cdot 8) \\
379(49 \cdot 5) \\
197(20 \cdot 7)\end{array}$ & $\begin{aligned} 5 \cdot 6(0 \cdot 2) \dagger \\
4 \cdot 5(0 \cdot 2) \dagger \\
19 \cdot 8(1 \cdot 4)^{\star} \\
232(34)^{\star} \\
122(13)^{\star}\end{aligned}$ \\
\hline $\begin{array}{l}\text { Neurohormonal data } \\
\text { Sympathetic nerve activity (bursts/min) } \\
\text { Sympathetic nerve activity (bursts/100 heart beats) } \\
\text { Plasma noradrenaline (nmol/l) } \\
\text { Plasma atrial natriuretic factor (pmol/l) }\end{array}$ & $\begin{array}{l}49 \cdot 2(10 \cdot 1) \\
51 \cdot 0(8 \cdot 7) \\
2 \cdot 9(1 \cdot 1) \\
59 \cdot 7(14 \cdot 6)\end{array}$ & $\begin{array}{l}24 \cdot 5(4 \cdot 7) \dagger \\
37 \cdot 5(5 \cdot 2)^{\star} \\
1 \cdot 7(0 \cdot 5) \\
31 \cdot 6(10 \cdot 7)^{\star}\end{array}$ \\
\hline
\end{tabular}

a5 subjects.

$\star \mathrm{P}<0.05 ;+\mathrm{P}<0.005$
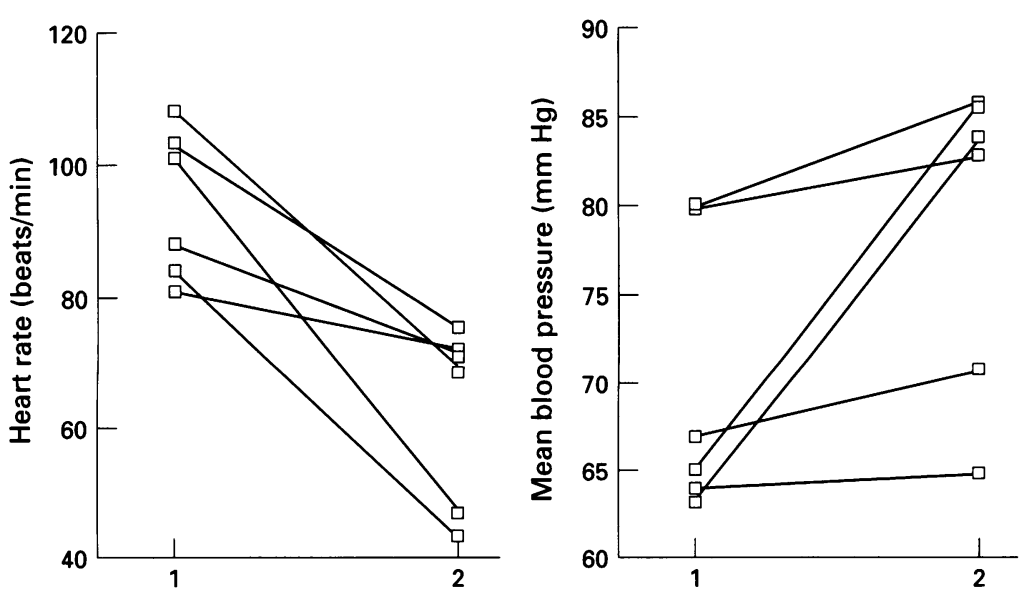

Figure 2 Plots of heart rate and mean arterial blood pressure immediately before addition of metoprolol (time 1) and after long term treatment (time 2). Average heart rate was significantly lower $(P<0.005)$, and average mean arterial pressure significantly higher $(P<0.05)$ after $\beta$ blockade.

\section{Results}

Mean data from the six subjects restudied while on metoprolol (table 1), used to assess the effects of long term treatment, will be referred to as the group mean. Group means for haemodynamic, echocardiographic, and neurohumonal variables before metoprolol and on metoprolol are presented in table 2 . Individual data points are presented in figs 2-4.

\section{HAEMODYNAMIC CHANGES}

Long term metoprolol treatment was associated with increases in systolic blood pressure $(\mathrm{P}<0.05)$ and mean blood pressure $(\mathrm{P}<$ $0.05)$ and decreases in heart rate $(P<0.005)$ (table 2). In five subjects calf blood flow increased threefold $(P<0.05)$, and there was a corresponding decrease in calf vascular resistance $(P<0.005)$ (fig 4$)$. In the sixth subject calf blood flow was undetectable at baseline by this technique and it was $1.5 \mathrm{ml} / \mathrm{min} / 100$ $\mathrm{ml}$ calf volume on restudy. There was a similar increase in blood pressure and decrease in heart rate in the one subject restudied on sotalol (table 1), but in contrast to metoprolol treated patients, calf vascular resistance rose, from $30 \cdot 2$ to $58 \cdot 2$ Units, on the $\beta$ adrenoceptor blocker.

\section{ECHOCARDIOGRAPHIC MEASUREMENTS}

Left ventricular end diastolic and end systolic diameters decreased significantly in metoprolol treated subjects (table 2; fig 3). These changes were associated with significant increases in fractional shortening. Calculated left ventricular mass and mass index decreased in all six subjects. There were qualitatively similar changes in these echocardiographic variables in the sotalol treated subjects-for example, fractional shortening increased from $13 \%$ to $27 \%$.

\section{NEURAL AND HORMONAL CHANGES}

Muscle sympathetic nerve burst frequency fell in all six metoprolol treated subjects ( $P<$ 0.005 ) (table 2, fig 4). These changes in pulse synchronous sympathetic outflow remained significant even when expressed as burst incidence, by adjusting for reductions in heart rate $(P<0.005)$. There were corresponding reductions in plasma noradrenaline concentrations $(P \sim 0.07)$ and plasma atrial natriuretic factor $(P<0.05)$ (table 2; fig 4$)$. There was no relation between the relative reduction in muscle sympathetic burst incidence and the initial heart rate of these subjects $(r=0.6$, $P \sim 0 \cdot 18 ; n=6$ ).

By contrast, sympathetic nerve burst frequency increased $50 \%$ in the subject restudied on sotalol (from 22 to 33 bursts $/ \mathrm{min}$ ) and burst incidence by $81 \%$ (from 26 to 47 bursts $/ 100$ heart beats). Plasma noradrenaline concentrations were $1.5 \mathrm{nmol} / 1$ on both study days, and plasma atrial natriuretic factor fell from $22 \cdot 5$ to $15 \mathrm{pmol} / 1$.

\section{AGGREGATE DATA}

There were correlations between muscle sympathetic nerve activity at baseline and changes 

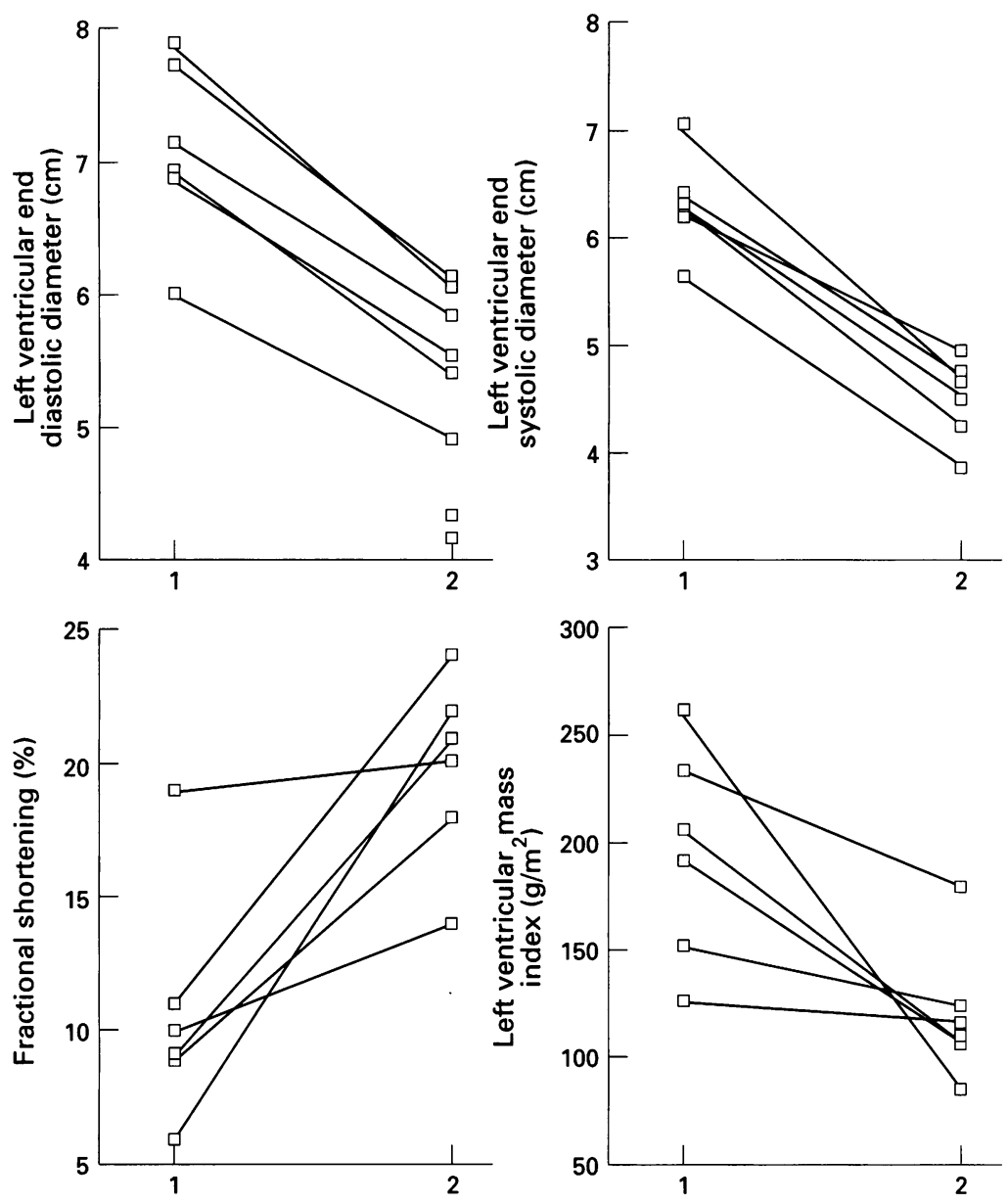

Figure 3 Plots of left ventricular end diastolic and end systolic diameters, fractional shortening, and left ventricular mass index immediately before addition of metoprolol (time 1) and after long term treatment (time 2). Average ventricular dimensions were significantly lower $(P<0.005)$, fractional shortening significantly greater $(P<0.05)$, and left ventricular mass significantly reduced $(P<0.05)$ on follow up.

in muscle sympathetic nerve burst frequency $(r=-0.90, \mathrm{P} \sim 0.01 ; \mathrm{n}=7$ ), muscle sympathetic nerve burst incidence $(r=-0 \cdot 81$, $\mathrm{P} \sim 0.05 ; \mathrm{n}=7$ ), and plasma noradrenaline concentrations $(r=-0.76, \mathrm{P} \sim 0.08 ; \mathrm{n}=6)$ between the first and second study. There was also a correlation between changes in muscle sympathetic nerve activity and changes in plasma noradrenaline concentration $(r=0 \cdot 79$, $P \sim 0.06 ; n=6$ ) between the first and second study.

\section{Discussion}

Chronic $\beta$ adrenoceptor blockade might benefit patients with dilated cardiomyopathy by antagonising the adverse effects of neurally released and circulating catecholamines on $\beta$ adrenergic receptors and on cardiac myocytes, ${ }^{3}$ or by attenuating efferent sympathetic traffic to the heart and peripheral vasculature. Attenuation of central sympathetic outflow should confer greater long term benefit, since peripheral $\beta$ adrenoceptor blockade leaves $\alpha$ adrenoceptor mediated vasoconstriction and renal sodium retention unopposed, and the heart and periphery are not shielded from the vasoconstrictor actions of other neurotransmitters coreleased by noradrenergic nerves, such as neuropeptide Y. ${ }^{23}$ Moreover, such generalised sympathoinhibition could also explain the sustained benefits achieved by the $\beta_{1}$ selective antagonist metoprolol, even though the failing heart has a relatively higher proportion of $\beta_{2} / \beta_{1}$ adrenergic receptors than the normal heart. ${ }^{56}$

Activation of the sympathetic nervous system in heart failure has been attributed to impairment of inhibitory afferent input from arterial and cardiopulmonary mechanoreceptors, and recruitment of sympathetic excitatory afferent input from underperfused skeletal muscle. ${ }^{317}$ Muscle sympathetic nerve burst frequency in patients with heart failure appears to be positively related to pulmonary arterial diastolic pressure, and inversely related to left ventricular stroke work index. ${ }^{24}$ Consequently, any improvement in these haemodynamic indices might reduce sympathetic outflow reflexively. However, in a substudy of 41 subjects enrolled in the metoprolol in dilated cardiomyopathy trial, those randomised to metoprolol experienced increases in ejection fraction after 12 months of treatment comparable to those of our subjects (from $21 \%$ to $34 \%$ ), as well as increases in cardiac output, yet resting arterial noradrenaline concentrations at that time were no lower than values in the placebo treated group, and net myocardial noradrenaline release was similar in placebo and metoprolol treated subjects, both at rest and during exercise. ${ }^{18}$

There are limitations inherent in this indirect estimate of sympathetic nerve activity ${ }^{19}$ that are exacerbated in heart failure, a condition in which increased noradrenaline concentrations reflect both increased spillover into plasma and decreased regional or total body clearance. ${ }^{2} 20$ The approach used in the present study is fundamentally different: this is the first study in dilated cardiomyopathy to examine directly the effects of long term $\beta$ adrenergic blockade with metoprolol on central sympathetic outflow to calf muscle, and at the same time assess a functional consequence of sympathetic nerve discharge to this bed by measuring calf vascular resistance distal to the recording electrode. Our objective was to test the hypothesis that muscle sympathetic nerve activity diminishes in subjects with dilated cardiomyopathy who improve after long term $\beta$ adrenoceptor blockade. Our principal finding was that efferent postganglionic muscle sympathetic nerve activity decreases in subjects who respond to long term treatment with metoprolol. The subjects in the present study had improvement in their symptoms, increases in blood pressure, and significant improvement in their left ventricular size and function. There was a $50 \%$ reduction in sympathetic burst frequency and a $62 \%$ reduction in resistance to blood flow in the calf, the major muscle bed distal to the recording electrode. These changes contrast with the consistency of muscle sympathetic nerve activity and calf vascular resistance over time in both normotensive and hypertensive subjects. ${ }^{1421}$

The duration of follow up of our metoprolol treated patients (approximately 20 months) should be emphasised. Haemodynamic 

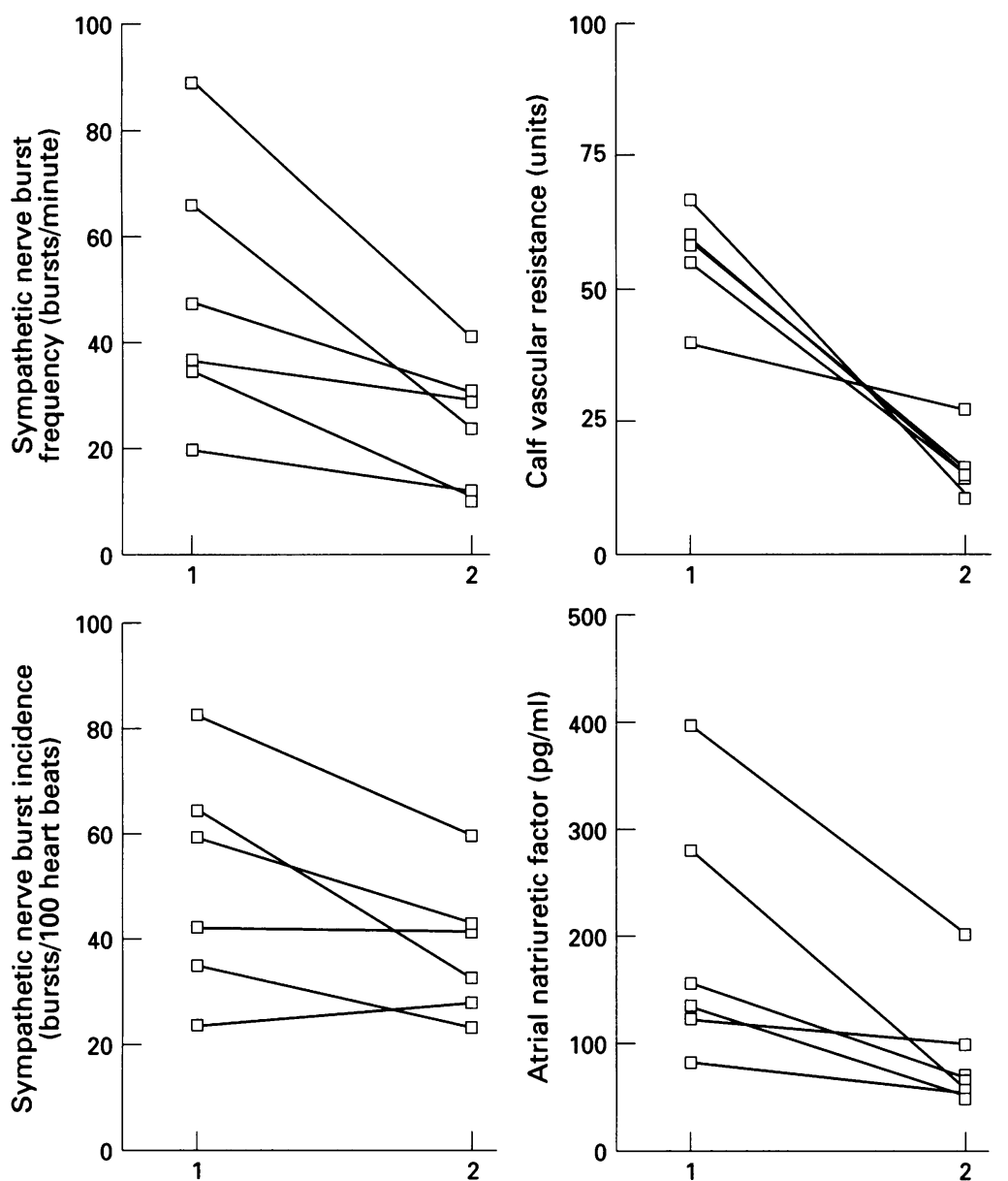

Figure 4 Plots of muscle sympathetic burst frequency, burst incidence, calf vascular resistance, and plasma atrial natriuretic factor concentration immediately before addition of metoprolol (time 1) and after long term treatment (time 2). There were significant reductions in mean values for muscle sympathetic nerve activity $(P<0.05)$, atrial natriuretic factor $(P<0.05)$, and calf vascular resistance $(P<0.005)$ between the first and second studies.

improvements in dilated cardiomyopathy elicited by $\beta$ adrenergic blockade are not always evident after two to three months. ${ }^{10}$ Indeed, the results of several short term (less than three months) placebo controlled double blind studies of $\beta$ adrenergic blockade therapy in congestive heart failure have been disappointing. ${ }^{22} 23$

The negative chronotropic effect of $\beta$ adrenergic blockade accounts for some of the reduction in muscle sympathetic nerve burst frequency in the present study. ${ }^{12}$ The pulse synchronous nature of muscle sympathetic nerve activity is a consequence of the restraining influence of afferent baroreceptor input on tonic sympathetic discharge. Since such input is highest during systole, and virtually absent during diastole, release of this tonic inhibition during each diastole provides the potential for a subsequent efferent burst. Nonetheless, chronic $\beta$ adrenergic blockade had an effect on muscle sympathetic nerve burst frequency that was independent of, and in addition to, its negative chronotropic action, because burst incidence (burst/100 heart beats) also fell from pretreatment levels.

Although arising from a single case, data from the sotolol treated subject are nonetheless interesting. If decreased heart rate and increased arterial and cardiac mechanorecep- tor afferent input were the principal explanation for the effects of $\beta$ adrenoceptor blockade on sympathetic nerve traffic, similar sympathoinhibition should have been observed in this subject. Haemodynamic indices improved, yet burst frequency was $50 \%$ higher and burst incidence was $81 \%$ higher (and calf vascular resistance distal to the recording electrode $93 \%$ higher) on restudy. These discordant findings indicate that mechanisms related to haemodynamic improvement cannot entirely explain the reductions in muscle sympathetic nerve activity observed after chronic metoprolol treatment in our subjects. Those reductions may result from a drug specific, perhaps central sympathoinhibitory, action of metoprolol. ${ }^{12}$

The concordance of neurovascular coupling in these subjects has not been described to date in any group of patients treated for heart failure. Over the short term (five weeks) enalapril causes modest calf vasodilatation $(+30 \%),{ }^{24}$ but ACE inhibitors appear to exert this effect through augmentation of endothelial function, ${ }^{25}$ rather than through sympathoneural withdrawal. ${ }^{26}$

As the improvement in our subjects' clinical status was temporally related to the addition of metoprolol, which was started because of progressive clinical deterioration despite hospital admission and several months of treatment, it would be implausible to attribute the haemodynamic and sympathoneural changes in our subjects either to spontaneous improvement or to a delayed response to their previous drug regimen. Transcardiac and total body noradrenaline spillover into plasma remain markedly increased despite long term treatment with digitalis, ACE inhibitors, or both. ${ }^{26}$ Long term placebo controlled trials of $\beta$ adrenoceptor blockade in dilated cardiomyopathy have revealed little or no change in haemodynamic variables ${ }^{97}$ or plasma noradrenaline concentrations ${ }^{1828}$ in placebo treated subjects. Because the objective of this study was to test the hypothesis that muscle sympathetic nerve activity diminishes in subjects with dilated cardiomyopathy who improve after long term treatment with metoprolol, our principal conclusion, namely that efferent postganglionic muscle sympathetic nerve activity decreases in those subjects who respond to such treatment, remains intact even in the absence of a placebo treated group. The delayed nature of this sympathoneural withdrawal ${ }^{12}$ may explain why patients do not experience haemodynamic compromise when exposed to gradually increasing doses of $\beta$ blockade.

Recently, we have suggested that activation of adrenergic drive to the diseased myocardium may be a causative mechanism linking sympathetic activation to adverse outcome in left ventricular dysfunction, and proposed that interventions that selectively modulate sympathetic outflow to the heart may benefit such patients, possibly if administered early before the development of generalised sympathetic activation. The hypothesis that interventions that attenuate sympathetic 
outflow to the heart will improve outcome in congestive heart failure has not been specifically addressed. ${ }^{3}$ Because there is concordance between changes in muscle sympathetic nerve activity and cardiac noradrenaline spillover, ${ }^{29}$ our present demonstration, by direct microneurographic recordings, that muscle sympathetic nerve activity decreases significantly in patients with idiopathic dilated cardiomyopathy who improve after their conventional therapy is supplemented suggests that metoprolol may be one such intervention.

Supported by the Heart and Stroke Foundation of Ontario (Grants Nos B1956, T2326), the Pettit Fund of the University of Toronto, and the University of Toronto Centre for Cardiovascular Research. JSF holds a clinician scientist award from the Ministry of Health of the Province of Ontario. MAR was a recipient of a fellowship from the Medical Research Council of Canada. $\mathrm{KH}$ was supported by postgraduate fellowship funds from the Division of Cardiology and the
Department of Medicine, University of Toronto, and by the Medical Research Council of Canada.

1 Cohn IN, Levine TB, Olivari MT, Garberg V, Lura D, Francis GS, et al. Plasma norepinephrine as a guide to
prognosis in patients with chronic congestive heart prognosis in patients with chronic
failure. $N$ Engl $\mathcal{F}$ Med 1984;311:819-23.

2 Kaye DM, Lambert GW, Lefkovits J, Morris M, Jennings G, Esler M. Neurochemical evidence for cardiac sympathetic activation and increased central nervous system norepinephrine turnover in severe congestive hear failure. $₹$ Am Coll Cardiol 1994;23:570-8.

3 Floras JS. Clinical aspects of sympathetic activation and parasympathetic withdrawal in heart failure. $\mathcal{f} \mathrm{Am}$ Coll Cardiol 1993;22:72-84A

4 Ferguson DW, Berg WJ, Sanders JS. Clinical and haemodynamic correlates of sympathetic nerve activity in normal humans and patients with heart failure: evidence from direct microneurographic recordings. $¥ \mathrm{Am}$ Coll from direct microneurog

5 Bristow MR, Ginsburg R, Umans V, Fowler M, Minobe W, Rasmussen R, et al. $\beta_{1}$ - and $\beta_{2}$-adrenergic-receptor w, Rasmussen $\mathrm{R}$, et al. $\beta_{1}-$ and $\beta_{2}$-adrenergic-receptor myocardium: coupling of both receptor subtypes to myocardium: coupling of both receptor subtypes to muscle contraction and selective $\beta_{1}$-receptor down-
regulation in heart failure. Circ Res 1986;59:297-309.

6 Bristow MR, Hershberger RE, Port JD, Rasmussen R. $\beta_{1}$ and $\beta_{2}$-adrenergic receptor-mediated adenylate cyclase stimulation in nonfailing and failing human ventricular myocardium. Mol Pharmacol 1989;35:295-303

7 Mann DL, Kent RL, Parsons B, Cooper G. Adrenergic effects on the biology of the adult mammalian cardiocyte. Circulation 1992;85:790-804.

8 Waagstein F, Hjalmarson A, Vernauskas E, Wallentin I. Effect of chronic beta-adrenergic receptor blockade in congestive cardiomyopathy. Br Heart $\mathcal{f}$ 1975;37: congestive

9 Waagstein F, Bristow MR, Swedberg K, Camerini F, Fowler MB, Silver MA, et al. Beneficial effects of metoFowler MB, Silver MA, et al. Beneficial effects of metoprolol in idiopath

10 Waagstein $\mathrm{F}$, Caidakl $\mathrm{K}$, Wallentin I, Bergh $\mathrm{CH}$, Hjalmarson A. Long term $\beta$-blockade in dilated cardiomyopathy: effects of short- and long-term metoprolo treatment followed by withdrawal and readmission of metoprolol. Circulation 1989;80:551-63.
11 Hainsworth R. Reflexes from the heart. Physiol Rev 1991;71:617-58.

12 Wallin BG, Sundolf G, Stromgren E, Aberg $H$ Sympathetic outflow to muscles during treatment of hypertension with metoprolol. Hypertension 1984;6: 557-62.

13 Bristow MR. $\beta$-Blockade with carvedilol selectively lower cardiac adrenergic drive in failing human heart [abstr]. $f$ Am Coll Cardiol 1992;19:146A

14 Floras JS, Hara K. Sympathoneural and haemodynamic characteristics of young subjects with mild essential hypertension. F Hypertens 1993;11:647-55.

15 Devereux RB, Reichek N. Echocardiographic determination of left ventricular mass in man. Circulation 1977; 55:613-8.

16 Floras JS. Sympathoinhibitory effects of atrial natriuretic factor in normal humans. Circulation 1990;81:1860-73.

17 Thames MD, Kunigawa T, Smith ML, Dibner-Dunlap ME. Abnormalities of baroreflex control in heart failure. f Am Coll Cardiol 1993;22:56-60A.

18 Anderson B, Hamm C, Persson S, Wikström G, Sinagra G, Hjalmarson A, et al. Improved exercise haemodynamic status in dilated cardiomyopathy after beta-adrenergic blockade treatment. $\mathcal{F}$ Am Coll Cardiol 1994;23 $1397-404$

19 Floras JS, Jones JV, Hassan MO, Osikowska BA, Sever PS, Sleight $P$. Failure of plasma norepinephrine to consistently reflect sympathetic activity in humans. Hypertension 1986;8:641-9.

20 Hasking G, Esler M, Jennings G, Burton D, Korner P. Norepinephrine spillover to plasma in patients with congestive heart failure: evidence of increased overall and cardiorenal sympathetic nervous activity. Circulation cardiorenal sym

21 Sundolf $G$, Wallin BG. The variability of muscle nerve sympathetic activity in resting recumbent man. F Physio (Lond) 1977;272:383-97.

22 Ikram H, Fitzpatrick D. Double blind trial of chronic ora beta blockade with metoprolol in congestive cardiomyopathy. Lancet 1981;i:490-3.

23 Currie PJ, Kelly MJ, McKenzie A, Harper RW, Lim YL Federman J, et al. Oral beta-adrenergic blockade with metoprolol in chronic severe dilated cardiomyopathy. Am Coll Cardiol 1984;3:203-9.

24 Cowley AJ, Rowley JM, Stainer K, Hampton JR. The effect of the angiotensin converting enzyme inhibitor enalapril, on exercise tolerance and abnormalities of limb blood flow and respiratory function in patients with severe heart failure. Eur Heart $f$ 1993;14:964-8.

25 Nakamura M, Fanakoshi T, Yoshida H, Arakawa N, Suzuki T, Hiramori K. Endothelium-dependent vasodilation is augmented by angiotensin converting enzyme lation is augmented by angiotensin converting enzyme inhibitors in healthy

26 Francis GS, Cohn JN, Johnson G, Thomas SR, Goldman $S$, Simon A. Plasma norepinephrine, plasma renin activity, and congestive heart failure-Relations to survival and the effects of therapy in V-HeFT II. Circulation 1993;87(suppl VI):V140-8.

27 Engelmeier RS, O'Connell JB, Walsh R, Rad N, Scanlon $\mathrm{PF}$, Gunnar RM. Improvements in symptoms and exercise tolerance by metoprolol in patients with dilated cardiomyopathy: a double-blind, placebo-controlled trial. Circulation 1985;72:536-46.

28 Woodley SL, Gilbert EM, Anderson JL O'Connell JB, Deitchman D, Yanowitz FG, et al. $\beta$-Blockade with bucindolol in heart failure caused by ischemic versus bucindolol in heart failure caused by ischemic versus idiopathic

29 Wallin BG, Esler M, Dorward P, Eisenhofer G, Ferrier C, Westerman $\mathrm{R}$, et al. Simultaneous measurements of cardiac noradrenaline spillover and sympathetic outflow to skeletal muscle in humans. $\mathcal{F}$ Physiol (Lond) 1992, 453:45-58. 